\title{
Trayectorias empresariales divergentes frente a contextos de privatización. Un estudio comparativo de dos empresas públicas argentinas
}

\section{Diverging entrepreneurial trajectories against the privatisation framework: A comparative study of two Argentinean public companies}

\author{
Juliana Frassa* \\ Leticia MuñIz-Terra** \\ Alejandro Naclerio**
}

\begin{abstract}
This article analyses the trajectories of two important Argentinean companies: Yacimientos Petroliferos Fiscales (YPF) and Astillero Rio Santiago (ARS), which in different ways faced privatisation by the national government. The comparative study of these two companies shows that the links between organisational actors and the socioeconomic conditions are never predetermined, since they are always the result of relational games.
\end{abstract}

Keywords: privatisation, State enterprise, entrepreneurial strategy, organisational change.

\section{Resumen}

En este artículo se analizan las trayectorias de dos importantes empresas argentinas: Yacimientos Petrolíferos Fiscales (YPF) y Astillero Río Santiago (ARs) que enfrentaron la privatización, por parte del gobierno nacional, de manera diversa. El estudio comparativo de ambas empresas evidencia que las articulaciones entre los actores participantes y las condiciones del contexto socioeconómico nunca están predeterminadas, ya que son el resultado, siempre particular, de juegos relacionales.

Palabras clave: privatización, empresa estatal, estrategia empresarial, cambio organizacional.

* Consejo Nacional de Investigaciones Científicas y Técnicas( Conicet), Argentina. Correo-e: mfrassa@ceil-piette.gov.ar.

** Universidad Nacional de La Plata, Argentina. Correos-e: leticiamunizterra@netverk.com.ar, leticiamunizterra@yahoo.com.ar, alejandro.naclerio@econo.unlp.edu.ar. 


\section{Introducción}

La política neoliberal de los años noventa trajo aparejadas importantes transformaciones en los modelos económicos de numerosos países, promoviendo el surgimiento de nuevas formas de producción y trabajo.

En Argentina, las tendencias propias de la globalización se expresaron conjuntamente con la implementación de un modelo económico neoliberal que derivó, entre otras cuestiones, en la desregulación de los mercados, la apertura comercial y la puesta en marcha de un profundo proceso de reestructuración productiva y privatización de las empresas públicas. En este artículo nos proponemos analizar y comparar las trayectorias de dos empresas públicas que se enfrentaron de manera diversa a un mismo contexto de privatización y ajuste del ámbito estatal; a saber, Yacimientos Petrolíferos Fiscales (YPF) y Astillero Río Santiago (ARs). Para ello se proponen dos niveles de análisis diferentes en cada caso. En primer lugar se aborda la relación dinámica de la empresa con su contexto en un momento de transformación estructural de la economía argentina, y en segundo término, los comportamientos desplegados por los distintos actores de cada organización.

La exposición se estructura en cinco partes. En la primera se presentan los principales postulados teóricos, provenientes de la sociología de las organizaciones, utilizados como guía de nuestro análisis; en la segunda se describen las principales características de las dos firmas analizadas; en la tercera se exponen las transformaciones estructurales ocurridas en la economía argentina durante los años noventa; en la cuarta se analizan las estrategias que desplegaron los actores de YPF y ARS frente a este nuevo contexto socioproductivo; y por último se señalan algunas conclusiones respecto a la complejidad de variables que intervienen en el análisis de las trayectorias empresariales y, particularmente, en la relación con su entorno.

\section{La empresa, el contexto y las estrategias de los actores}

Para definir a la empresa y su relación con el entorno asumimos las premisas de la corriente francesa de la sociología de las organizaciones (Reynaud, 1989; Bernoux, 1985; Crozier y Friedberg, 1990). Esta perspectiva concibe a la empresa como una organización productiva en la cual los sujetos interactúan para crear y reproducir reglas, valores y significaciones simbólicas.

Según esta corriente, las organizaciones sólo se pueden comprender a partir de las interacciones entre sus actores, entendiendo que toda organización es una construcción social inventada por actores relativamente autónomos, con recursos y capacidades específicas que, aunque con 
orientaciones divergentes, cooperan con miras a cumplir un objetivo común. Cada uno de estos actores, haciendo uso de los recursos y las fuentes de poder disponibles, desarrollará estrategias orientadas a alcanzar sus objetivos y a obtener mayores cuotas de poder para controlar las zonas de incertidumbre de la organización.

Alejándose tanto de la teoría estructural-funcionalista como de las corrientes interaccionistas en sociología, esta perspectiva concibe a la organización como "un universo de conflicto" y su funcionamiento como "el resultado de los enfrentamientos entre las racionalidades contingentes, múltiples y divergentes, de actores relativamente libres que utilizan las fuentes de poder de que disponen" (Crozier y Friedberg, 1990: 77). Lejos de un posicionamiento determinista, esta corriente enfatiza el carácter indeterminado de la acción colectiva, ya que los actores son quienes - dentro de las restricciones que les impone el sistema- disponen siempre de un margen de libertad que emplean de manera estratégica en sus interacciones con los otros.

Desde esta perspectiva se propone considerar a la organización como "el resultado de una serie de juegos en los cuales participan diferentes actores organizacionales y donde las reglas formales e informales [...] delimitan un abanico de estrategias racionales posibles" (Crozier y Friedberg, 1990: 114). En la concepción misma de juego los autores ven la posibilidad de conciliar las ideas de libertad de acción y determinismo estructural, ya que el jugador es libre pero debe, si quiere ganar, adoptar una estrategia racional en función de la naturaleza del juego.

En resumen, para esta perspectiva la organización es una construcción contingente donde se producen reglas sociales, siempre abiertas y en permanente reconstrucción, que aceptan y legitiman actores relativamente libres que actúan dentro de un esquema de racionalidad limitada (Bernoux, 1985).

Ahora bien, toda organización está inserta en un sistema de poder más amplio que constituye el entorno o contexto organizativo del que participa y del cual adopta características que integra a su propio sistema de acción. Sin embargo, el entorno constituye también una fuente de incertidumbre para la organización. El entorno, constituido por múltiples campos fraccionados, plantea a la organización exigencias fluctuantes, ambiguas y con frecuencia divergentes que constituyen, al menos potencialmente, fuentes de cambio para la organización.

El cambio en las organizaciones se comprende y analiza desde dos posturas bien diferenciadas. ${ }^{1}$ Por un lado, se afirma que las estructuras socioeconómicas juegan un rol preponderante imponiendo el cambio en

${ }^{1}$ La contradicción entre ambas perspectivas no se resuelve fácilmente y, en definitiva, depende de la concepción de la acción humana que se tenga y la teoría social que se adopte (Bernoux, 2002). 
las organizaciones. Esta postura, que asume una lógica económica y determinista, sostiene que factores como la tecnología, la competencia o el grado de estabilidad del entorno son coacciones inevitables que explican, en última instancia, todo cambio organizacional. En el análisis organizacional fue la teoría de la contingencia la primera en plantear que el diseño de la estructura organizacional siempre es contingente a las condiciones del entorno (Lawrence y Lorsch, 1967; Burns y Stalker, 1966). El contexto de privatización y las políticas macroeconómicas de corte neoliberal implementadas en Argentina en los noventa, desde esta perspectiva, constituirían las condiciones del entorno que explicarían las trayectorias seguidas por las empresas.

Desde esta perspectiva se asume un enfoque que limita el análisis de fenómenos organizacionales, en tanto elude el tratamiento de las interacciones complejas que conducen a comprender la relación entre conflicto y cooperación al interior de la organización. ${ }^{2}$

Por otro lado, está la postura que sostiene que el cambio sólo es posible en la medida en que lo aceptan los actores organizacionales que lo ponen en práctica. Si bien esta corriente acepta el peso de la coacción económica, no la concibe como determinante y asegura que el cambio dependerá, en definitiva, de la manera en que los actores lo acepten y administren. Los autores que asumen esta perspectiva (Linhart, 1997; Bernoux, 1985) acentúan las capacidades de los individuos y grupos para modificar sus relaciones y actuar sobre el devenir de las organizaciones. El cambio organizacional no se produce, entonces, únicamente por efecto de coacciones externas sino también, de manera endógena, por la capacidad y voluntad de los actores de definir de otra manera sus relaciones. Así, esta postura plantea que la respuesta que cada empresa adopta frente a los cambios externos varía, dentro de un conjunto de opciones limitadas por el desarrollo sociotécnico existente, de acuerdo con una multiplicidad de factores.

Ubicándonos en la segunda de las posturas descritas, planteamos que el cambio, en tanto respuestas particulares a situaciones también particulares, "no puede ser comprendido más que como un proceso de creación colectiva a través del cual los miembros de una determinada colectividad aprenden juntos, es decir, inventan y determinan nuevas formas de jugar el juego social de la cooperación y el conflicto, y adquieren las capacidades cognoscitivas, de relación y organizativas correspondientes" (Crozier y Friedberg, 1990: 29). El modo particular de resistencia y/o adaptación

\footnotetext{
${ }^{2}$ En estos enfoques incluimos los que, desde la perspectiva económica, conciben a la firma como forma de coordinación administrativa (Coase, 1937; Williamson, 1985), como un hecho estilizado institucional (Aoki, 1988, 2001) o como una unidad evolutiva y generadora de capacidades dinámicas (Nelson y Winter, 1982).
} 
de cada empresa a la situación cambiante del contexto dependerá, entre otras cuestiones, de la relación de fuerzas establecida en la organización, la cultura organizacional existente, el marco político de actuación y las habilidades y saberes acumulados por la firma (Linhart, 1997).

\section{Nuestros estudios de caso: breve reseña de dos empresas públicas}

Las empresas aquí analizadas constituyen ejemplos paradigmáticos de la voluntad estatal, que alcanzó su apogeo en la década de los cincuenta, de asumir la dirección del desarrollo económico nacional. Si bien ambas firmas presentan diferencias productivas y organizacionales insoslayables, ${ }^{3}$ es posible observar ciertas similitudes en su concepción como instrumentos promotores de soberanía nacional. Esta característica se expresó en las respectivas culturas organizacionales, que se construyeron en torno al carácter estatal y nacional de las empresas.

Presentamos entonces, brevemente, las características relevantes de cada una de estas firmas.

\subsection{Astillero Río Santiago: "voluntad nacional construyendo para el mar"s}

El Astillero Río Santiago, creado en 1953 bajo la dependencia del Ministerio de Marina, se ideó como parte de un ambicioso plan estratégico de industrialización encarado por el segundo gobierno de Perón, con el objetivo de fortalecer la industria pesada y fomentar la creación de un entramado industrial nacional. El astillero, especializado en la fabricación y reparación de diversos bienes de capital (tanto construcciones navales como mecánicas), fue creado para satisfacer, inicialmente, la creciente demanda interna de la marina mercante y la Armada Nacional.

Con un marco regulatorio de tipo proteccionista que promovía la construcción de buques en astilleros argentinos, el desarrollo de la industria naval se caracterizó por la fuerte intervención del Estado. El sector estatal no sólo ocupaba un lugar central en la oferta, al ser propietario de grandes astilleros, sino también en la demanda de buques y construcciones mecánicas mediante sus principales organismos y empresas (Empresas Líneas Marítimas Argentinas, YPF, Empresa Flota Fluvial del Estado Argentino y Ferrocarriles Argentinos), conformando un importante entra-

\footnotetext{
${ }^{3}$ En términos de dimensiones físicas, nivel de producción, facturación y puestos de trabajo, YPF fue ampliamente más relevante que el ARs, ya que constituía una de las mayores empresas nacionales, con emplazamientos en todo el país. El ARs tenía una fuerte impronta regional, pero de dimensiones más acotadas.

${ }^{4}$ Eslogan publicitario de la empresa hasta los años ochenta.
} 
mado productivo y comercial de carácter público. En este sector de actividad, el Estado cumplió cuatro roles fundamentales como regulador -estableciendo el marco normativo-, como productor y demandante de buques $y$, finalmente, como proveedor de mecanismos de financiamiento (CEP, 2005; FINA, 2001).

Con el correr de los años el ARs experimentó un proceso de expansión tanto en términos de producción y empleo como de capacidad instalada, que lo llevó a posicionarse, a principios de los años setenta, como el astillero más grande de Sudamérica. En el marco del modelo de industrialización por sustitución de importaciones, la empresa desarrolló un amplio espectro de producción conexa a la naval (grandes motores diesel y centrales termoeléctricas, recipientes a presión para la industria petrolera, elementos ferroviarios, compuertas para diques, componentes nucleares) que implicó la creación de importantes eslabonamientos productivos, incorporación de nuevas tecnologías y desarrollo de nuevos saberes y capacidades (ARS, 2004). En su carácter de empresa integrada, el ARS construía casi todos los componentes del buque (motor, casco, equipos de cubierta, grúas), para lo cual contaba con una importante infraestructura y mano de obra altamente calificada.

Hasta los ańos ochenta el Astillero Río Santiago se podía caracterizar como una empresa de producción diversificada, con una extendida industria auxiliar, fuertemente dependiente del Estado y promotora de altos niveles de ocupación (CEP, 2005). Por su origen como empresa que dependía de la Armada, la organización interna del ARs se caracterizaba por presentar una estructura fuertemente burocrática, piramidal y jerarquizada, así como un discurso organizacional de carácter estatista que hacía hincapié en la consolidación de la soberanía nacional mediante la construcción local de buques.

Si bien los objetivos originales de la empresa respondían a metas estratégicas más que a criterios de rentabilidad económica, el ARs presentó resultados operativos positivos durante su desarrollo en el mercado interno debido a que el Estado proveía un nivel de demanda sostenible que garantizaba la rentabilidad de los activos de la empresa a largo plazo.

\subsection{Yacimientos Petroliferos Fiscales: la "gran empresa nacional"}

La empresa Yacimientos Petrolíferos Fiscales (YPF) fue creada por el gobierno en 1922, a raíz del descubrimiento de petróleo crudo en el sur argentino. Con el correr de los años esta compañía extendió su actividad productiva a todo el país y se convirtió en la firma nacional explotadora de recursos naturales más relevante de la nación. 
Al igual que en los demás países petroleros, aquí se desarrolló una gran empresa integrada verticalmente, esto es, "una empresa activa en todas las fases de producción: exploración, desarrollo, transporte, almacenamiento, refinación, distribución y comercialización al por menor" (OIT, 1998: 5).

Los productos finales obtenidos y comercializados eran muy diversos. Se producían: naftas súper y normal, jp1 (aerocombustibles para el transporte), azufre, gas oil doméstico y comercial, carbón de petróleo, parafinas, aceites lubricantes, asfaltos, fuel oil y una gran cantidad de materias primas para la industria petroquímica (Repsol-YPF, 2004).

La función principal de YPF era satisfacer las necesidades de petróleo, incrementar la producción de este recurso natural y reducir, en consecuencia, la dependencia del abastecimiento externo. Así, si bien la búsqueda de rentabilidad era un punto a alcanzar para que la compañía pudiera obtener beneficios y mantenerse o crecer en el mercado, éste no era el fin más importante de la empresa.

Al ser una compañía del Estado, YPF solía responder a las necesidades que tuviera el país persiguiendo objetivos que estaban estrechamente vinculados con la política económica de los respectivos gobiernos en turno. De esta forma, la larga historia de la empresa petrolera argentina, estuvo indisolublemente ligada a las diferentes fases de la evolución del modelo de sustitución de importaciones, implementado tanto en sus versiones marcadamente estatistas (Juan Domingo Perón, Arturo Illia), como en aquella otra orientada a abrir la participación de capitales privados (Arturo Frondizi).

Asimismo, ypF era una de las empresas públicas que más personal empleaba. Por ejemplo, en 1989 su plantilla estaba constituida por 37,046 trabajadores petroleros. De ellos, 56\% eran operarios, $21.3 \%$ técnicos, $11.6 \%$ administrativos y el $11 \%$ restante eran profesionales (Boletín de Informaciones Petroleras, 1989).

La visión estatista de la actividad petrolera propició, además, un importante proceso de interiorización del discurso industrialista que colocaba el acento en el control estratégico de los recursos naturales como pilar de la soberanía nacional.

Así, la importancia de la firma petrolera no estuvo limitada a su dinámica actividad productiva, sino que ayudó también al crecimiento socioeconómico y laboral de las regiones donde se emplazaba, incentivando el desarrollo de un modelo social que sintetizaba las garantías y oportunidades que ofrecía el Estado social argentino a sus trabajadores (derechos y protección social) (Svampa y Pereyra, 2003). YPF desplegó una estrategia de desarrollo urbano y regional al subsidiar al territorio donde se asentaba, logrando traspasar su función productiva para intro- 
ducirse profundamente en los espacios de la vida cotidiana de los habitantes de la región, de los trabajadores petroleros y sus familias.

\section{La transformación del contexto de desarrollo en la Argentina de los noventa}

A principios de los años setenta se produjo en los países desarrollados una profunda crisis del régimen de acumulación. ${ }^{5}$ Este régimen se caracterizaba por la organización fordista de la producción que implicaba la producción de bienes de consumo masivos, una profunda mecanización del trabajo y aumentos crecientes de la productividad laboral (Bustelo, 2003).

La crisis de este régimen de acumulación que había primado en la $e$ dad de oro del crecimiento económico (1945-1970), obedeció principalmente a las limitaciones propias del modelo productivo y a la creciente globalización de las relaciones económicas. Mientras que el modelo de organización del trabajo fordista comenzaba a mostrar una importante caída en las tasas de productividad, las políticas de corte neoclásico y la globalización se expandían aceleradamente

A comienzos de los años ochenta el cambio de orientación política ocurrido en Estados Unidos y Gran Bretaña amplió la ofensiva del neoliberalismo. Las políticas de estos países tuvieron una influencia directa en el plano internacional desencadenando una verdadera dinámica mundial de desregulación y privatización que, a su vez, promovieron y consolidaron los distintos organismos internacionales.

El Consenso de Washington, que se convirtió en la guía que debían seguir los países en desarrollo, indicaba las medidas de apertura, desregulación y privatización como las soluciones para lograr el crecimiento económico. Los organismos internacionales (sobre todo la омс, el вм y el FMI) promovían estas políticas asistiendo técnica y crediticiamente a los países alineados en el consenso establecido.

Estas nuevas políticas económicas reemplazaron la estrategia de industrialización por sustitución de importaciones implementada regionalmen-

\footnotetext{
${ }^{5}$ El régimen de acumulación refiere al modo de transformación conjunta y compatible de las normas de producción y consumo. Desde la perspectiva de la teoría de la regulación, el sistema económico se organiza según un conjunto de regularidades de origen institucional que compensan su inherente inestabilidad. De esta forma se distancian de la visión neoliberal que sostiene el libre equilibrio de la oferta y la demanda, y analizan el desarrollo del capitalismo a partir de un estudio de la particular combinación de las regulaciones institucionales durante periodos prolongados del capitalismo.

Para sus principales referentes, entre quienes cabe destacar a M. Aglietta, R. Boyer y B. Coriat, el régimen de acumulación que prevaleció hasta los ańos sesenta se traducía en un sistema capitalista que debía su existencia a una articulación más o menos armónica entre la producción y el consumo, viabilizada por un conjunto de instituciones de regulación como las normas y los valores internalizados, y los mecanismos institucionales formales (Boyer, 1987).
} 
te. La inviabilidad y el mal manejo de la protección económica favoreció la llegada de los aires de cambio liberales, que tendieron a demonizar el papel del Estado en la economía y a enfatizar las virtudes de la mano invisible del mercado (Fishlow, 1990). Así, en los últimos 30 años los gobiernos volvieron atrás con sus políticas regulatorias, favoreciendo, con la apertura de la economía, el libre juego de la oferta y la demanda.

En Argentina podemos identificar al menos tres elementos fundamentales que operaron en la estrategia económica iniciada en los años setenta y consolidada en los ochenta y noventa: la privatización de empresas públicas proveedoras de bienes y servicios; la desregulación o reconfiguración del marco regulatorio ${ }^{6}$ de la economía en general y de sectores en particular; y la profundización del proceso de apertura externa (Azpiazu, 1995). Dichos elementos tuvieron una impronta fundamental en el sector industrial, modificando de manera radical tanto su nivel como su composición. ${ }^{7}$

En la teoría de la regulación (Boyer, 1987) se señala que en la década de 1990 la desregulación caracteriza la forma institucional competencia, la cual favorece la concentración económica. Constatamos, entonces, una reconfiguración de la competencia donde la distribución, la comercialización y, sobre todo, las finanzas dominan el proceso de generación de riquezas. El poder que adquirieron estos sectores, y la política de apertura externa, fueron minando el corazón del sistema productivo nacional anterior.

Según sostiene Basualdo (2000), las reformas estructurales posteriores al periodo de crisis de los años ochenta se sustentan en el acuerdo entre los actores privados (locales y externos) que jugaron un rol determinante en la implementación de la política pública. En este sentido, el flujo de inversión extranjera directa asociado al proceso de privatizaciones y al proceso de fusión y adquisiciones de grandes corporaciones nacionales se desarrolló en un contexto que asumió explícitas reglas de rentabilidad. Dichas reglas se establecieron para garantizar la paz económica y social firmada por los compradores y vendedores.

Cabe señalar que la política de privatizaciones en Argentina adquirió un carácter fuertemente ofensivo y cortoplacista, que no consideraba la posibilidad de establecer regímenes mixtos de propiedad de las empresas

\footnotetext{
${ }^{6}$ En términos generales, la desregulación no implicó la regulación propia de los mecanismos del mercado, sino que por el contrario, como seńala Azpiazu, la regulación "se transfirió a determinados agentes económicos que, por la propia morfología de los mercados y su posicionamiento oligopólico, cuentan con amplios márgenes para regular el funcionamiento de los mismos” (1995: 161).

${ }^{7}$ En términos generales, las consecuencias de la implementación de estas políticas fueron la concentración de la propiedad, la consolidación de nuevos monopolios y oligopolios, la reestructuración regresiva y la pérdida de dinamismo del sector industrial (Kosacoff, 2000).
} 
o de estrictas regulaciones operativas. El objetivo de esta política fue lograr el más rápido y completo vaciamiento de los activos estatales

Por un lado, los compradores fueron firmas multinacionales que buscaban expandirse en el mercado interno y externo. Por otro, los vendedores fueron grupos nacionales que buscaban la valoración monetaria de sus activos. Este esquema, de aumento de rentabilidad, implica literalmente la privatización de la renta. Más aún, significa la garantía de beneficio en un contexto de flexibilización de costos (sobre todo del trabajo).

A partir de 1995 el capital extranjero se consolida en detrimento del capital nacional por causa de factores financieros y de transferencia de acciones de firmas privatizadas y grandes firmas locales. De esta manera, la configuración organizacional de la industria es coherente con una tendencia a una mayor concentración acompañada de políticas de subcontratación.

Los beneficios financieros (y/o especulativos) no necesariamente se tradujeron en inversión productiva, lo que generó e, incluso, amplió el deterioro de la producción industrial. La obtención de rentas se logró gracias a la explotación de mercados monopólicos en los servicios públicos y oligopólicos en ciertos sectores particulares, como las industrias automotriz, ${ }^{8}$ petrolera y mineral.

En resumen, las reformas estructurales impusieron en Argentina una integración y sumisión sin restricciones a la mundialización financiera. En tal sentido, el gran volumen de capital recibido, incluidas las inversiones en actividades productivas, buscó una tasa de beneficio bastante más elevada que la media histórica.

Teniendo en cuenta este proceso de transformación del contexto de desarrollo en Argentina, en los siguientes apartados analizamos los cambios que tuvieron las firmas estudiadas, ARS e YPF, considerando el entorno en el que se insertan las empresas, así como el comportamiento de los actores que intervienen en las mismas. Así, estas dos empresas constituyen ejemplos paradigmáticos del retraimiento del Estado, en tanto regulador de mercados y productor de bienes y servicios, y de la aplicación de políticas de ajuste y desregulación ocurridas.

\footnotetext{
${ }^{8}$ La industria automotriz se vio favorecida por una legislación especial de subvenciones diferenciales en el marco del Mercosur. Sólo dos sectores se beneficiaron por exenciones y un régimen especial. Uno es la industria automotriz en coordinación con la industria brasileńa, sobre lo cual se han realizado varios trabajos. El otro sector es la industria del azúcar, cuya legislación especial (obtenida por poder de lobby de los industriales argentinos) protege a los productores locales de la competencia brasileña.
} 


\section{Enfrentar el cambio: las estrategias de los actores en el devenir de las trayectorias empresariales}

El nuevo contexto macroeconómico y la profunda transformación de la función del Estado en la economía ${ }^{9}$ afectaron y condicionaron fuertemente a estas empresas. Sin embargo, cada una de ellas respondió al cambio del entorno de manera diversa conformando, desde ese entonces, trayectorias divergentes. Veamos a continuación cuáles fueron las estrategias particulares desplegadas por los participantes en cada una de estas organizaciones.

\subsection{ARS: resistencia laboral y subvención estatal}

El tipo de cambio, que encareció los costos de los productos argentinos en el ámbito internacional, el cierre y/o privatización de las grandes empresas estatales y la apertura brusca al mercado externo fueron los rasgos del nuevo modelo económico que modificó por completo las reglas de juego en las que se desarrollaba el ARs. En ese contexto se introdujeron políticas de liberalización en el sector de construcción naval y transporte marítimo que establecían la desregulación del transporte, la eliminación del régimen de bandera nacional (decreto 1771/91), la disolución del Fondo de la Marina Mercante (principal fuente de financiamiento para la construcción naval local) y la puesta en práctica de estrategias privatizadoras en los astilleros estatales (Frassa, 2006). Como parte de este programa, en 1991 el ARs es declarado sujeto a privatización, según lo dispuesto por la ley $24,045 .{ }^{10}$

Como resultado de estas medidas, que favorecían la importación de embarcaciones y la disminución de los activos estatales, ${ }^{11}$ se produjo la caída de la demanda interna de buques y la consiguiente paralización de la producción en el ARs. Con el objetivo de sanear la empresa antes de su traspaso a manos privadas, la dirección puso en práctica un plan de racionalización para reducir sus efectivos. Mediante la modalidad de retiros voluntarios, entre los años 1990 y 1993 el ARs redujo su personal en 60\%: pasó de 2,460 efectivos a sólo 1,036.

\footnotetext{
${ }^{9}$ Dicha transformación se vio concretamente plasmada en la Ley 23,696 de Reforma del Estado, promulgada en agosto de 1989, que declara el estado de emergencia de todo el ámbito público, la intervención de todos los entes, empresas y sociedades estatales y la privatización total o parcial de las empresas públicas.

${ }^{10}$ De manera específica, la ley nacional 24,045, promulgada en diciembre de 1991, declara sujetas a privatización a numerosas entidades que operaban en el ámbito del Ministerio de Defensa, entre ellas el ARs.

${ }^{11}$ Cabe recordar que el Estado era el principal demandante de los buques y construcciones mecánicas del ARs.
} 
Durante estos tres ańos se desarrollaron agudos conflictos laborales en los que los trabajadores, acompañados por sus dirigentes sindicales, reclamaron la reactivación y permanencia del ARS en la órbita estatal y el pago de salarios adeudados (Pérez, 2003; Montes, 1999).

Como resultado de las estrategias llevadas a cabo por los actores, finalmente el ARs logró evadir la privatización nacional y ser transferido en 1993 al gobierno de la provincia de Buenos Aires. El rescate de la empresa no la salvó, sin embargo, de la política de ajuste aplicada a todo el ámbito estatal. En 1995 se aprobó la instalación de la Zona Franca de La Plata en el predio perteneciente hasta entonces al astillero, dejándolo en posesión de sólo 23 de sus 229 hectáreas originales. Esta medida provocó la pérdida de numerosas instalaciones y equipos, con la consiguiente reducción de su capacidad instalada. Asimismo, el ajuste en el presupuesto provincial implicó que su maquinaria se volviera obsoleta por falta de reemplazo, el congelamiento de la plantilla de trabajadores y la escasez de recursos financieros para emprender nuevas obras.

En síntesis, como consecuencia de la implementación de políticas macroeconómicas de corte neoliberal, el ARs perdió competitividad en los mercados nacional e internacional, disminuyó el nivel y grado de diversificación de su producción, perdió su industria auxiliar, redujo su plantilla de trabajadores calificados y redujo su capacidad; todo ello, sumado a los sucesivos cambios en la dirección de la empresa, implicó el deterioro y/o pérdida de rutinas organizacionales. Ni la racionalización de la actividad productiva ni la reducción de la plantilla de trabajadores tuvieron efectos positivos en el desempeño económico del astillero. Dichas medidas sólo implicaron la pérdida de capacidades productivas y técnicas acumuladas en la empresa.

Cabe señalar que el proceso de ajuste aplicado al ARs no se acompañó de una estrategia empresarial de modernización (Dombois y Pries, 1993, Linhart, 1997) para enfrentar los desafíos que el cambio de contexto representaba. La empresa logró evadir la política de privatización y mantener su funcionamiento productivo conservando, aunque con algunas variaciones, su estructura y funcionamiento tradicionales.

\subsubsection{Las estrategias de los actores frente al cambio}

La transformación del modelo económico fue el marco de actuación, de restricciones y oportunidades en el que los actores desplegaron diversas y contrapuestas estrategias que influyeron en el devenir de la empresa. En este sentido, planteamos que la evasión de la privatización y la subsistencia productiva del ARs se explica por la articulación peculiar de las estrategias puestas en práctiva por los actores: la acción de resistencia a la 
privatización de los trabajadores y la estrategia político-estatal de subvención económica.

En primer lugar, debemos diferenciar tres actores gubernamentales con intereses y estrategias diversas sobre la empresa. Por un lado identificamos al gobierno nacional que, respondiendo al objetivo de reducir el déficit público, se propuso la desvinculación de todo activo productivo y la puesta en práctica de una fuerte política de ajuste.

Frente a la dificultad de hallar en el corto plazo un comprador para el astillero, ${ }^{12} \mathrm{y}$ al importante grado de resistencia expresado por los trabajadores y la comunidad local a la privatización, el Poder Ejecutivo nacional decidió pactar una salida políticamente viable transfiriendo la empresa al gobierno provincial. Esta alternativa le permitía al gobierno nacional desentenderse del conflicto social cada vez más extendido en la región, ${ }^{13}$ y continuar avanzando con su política privatista en otras grandes empresas que le redituaran mayores ganancias. Recordemos que frente a la dimensión de las otras empresas estatales en proceso de privatización (YPF, Entel, Gas del Estado, Aerolíneas Argentinas, etc.), el ARs no constituía una empresa prioritaria, lo cual favoreció que se pospusiera el intento de privatización.

Por otro lado identificamos a la Marina, órgano responsable de la dirección de la empresa desde sus orígenes, quien tuvo una estrategia ambivalente. Aunque la gestión empresarial se hallaba sujeta a las directivas generales dispuestas por el Poder Ejecutivo, gozaba de un importante margen de maniobra al interior de la empresa. Si bien acató e implementó dichas directivas, ante la acción de resistencia de los trabajadores la dirección adoptó una actitud más permisiva, un dejar hacer, con el objetivo de mantener, en la medida de lo posible, la capacidad productiva en funcionamiento y conservar cierto poder sobre la empresa. La Marina buscó salvaguardar sus propios intereses y recursos que se veían amenazados por la política privatista del gobierno nacional. Sin embargo, finalmente, su estrategia no fue exitosa ya que con la provincialización la Marina perdió toda injerencia sobre la empresa.

El tercer actor estatal en este esquema fue el gobierno de la provincia de Buenos Aires, cuya decisión de hacerse cargo de la empresa respondió, principalmente, a una estrategia de carácter político-económica. Política porque el control del ARs permitió sumar una nueva fuente de poder para la utilización partidaria y calmar el conflicto regional que cobraba

\footnotetext{
${ }^{12}$ La profunda recesión internacional del sector de construcción naval desfavorecía la aparición de un comprador para la empresa.

${ }^{13}$ Recordemos que la privatización de la destilería de YPF y el cierre de otras fábricas en la región afectaron de manera considerable a las localidades tradicionalmente industriales de Beriso y Ensenada, cuya configuración ocupacional pasó a presentar un elevado porcentaje de desocupación y subocupación.
} 
cada vez más visibilidad; y económica porque, sumado a la transferencia de fondos que realizó la nación, la instalación de una zona franca en la territorio de la empresa permitió al gobierno obtener ganancias comerciales en un espacio que, en el marco del modelo económico de los noventa, era improductivo. Los beneficios que obtenía así el gobierno provincial tenían el costo de subvencionar económicamente al astillero.

Como vemos, cada uno de los actores gubernamentales llevó a cabo la estrategia racional más conveniente a sus intereses, aunque no siempre lograra alcanzar su objetivo máximo. Dichas estrategias tuvieron una solución satisfactoria aunque no óptima, entendidas como estrategias racionales en términos contextuales. ${ }^{14}$

Por su parte, los trabajadores del ARs emprendieron, entre 1990 y 1993 , conflictos laborales abiertos ${ }^{15}$ de carácter defensivo y creciente politización en respuesta al intento de privatización y ajuste. La acción de resistencia llevada a cabo por la dirigencia gremial, los trabajadores y mandos medios fue un elemento importante en el devenir del conflicto, pues condicionó las estrategias desarrolladas por los actores gubernamentales.

En primer lugar, coincidimos con el análisis de Pérez Pradal (2003), quien señala que la tradición de lucha y organización del sindicato del ARS en los años setenta y la característica democrática y pluralista de su estructura sindical, habrían sido factores que favorecieron tal resistencia. El sistema de representación gremial existente habría propiciado la democratización de las decisiones, el control de la cúpula sindical por parte de los trabajadores de base y la rápida organización de la acción colectiva.

En cuanto a los conflictos abiertos, la estrategia de los trabajadores del ARs fue comprometer a la comunidad local en el reclamo laboral y establecer alianzas con otros sectores de trabajadores públicos en lucha. La publicidad y pluralidad alcanzada por el conflicto (marchas a edificios públicos, aparición en medios masivos de comunicación) fue, sin duda, otro elemento clave de la estrategia de lucha.

En síntesis, los trabajadores desarrollaron una estrategia defensiva en su intento por evadir la política que le imponían los otros actores involucrados (el gobierno nacional, principalmente). Ahora bien, dicha estrategia y el compromiso demostrado con la reactivación de la empresa, sólo se

${ }^{14}$ Aquí seguimos las ideas de Simon (1969), quien centrado en el análisis del proceso decisional, plantea analizar las acciones en el marco de una racionalidad limitada. Según este modelo, los criterios de satisfacción de quien toma la decisión están influidos por las características del contexto, por ello las estrategias del actor deben ser siempre comprendidas dentro del sistema de acción en el que se inscriben.

${ }^{15}$ Estos conflictos tuvieron diversas modalidades: ocupación de fábricas, falta de colaboración de los trabajadores (asistían pero sin desarrollar actividad laboral), movilizaciones multitudinarias a centros de poder gubernamental, cortes de rutas y ocupación de edificios públicos. Las principales demandas y consignas fueron pago de salarios adeudados, oposición a las privatizaciones y defensa de la industria nacional. 
pueden comprender en profundidad considerando los soportes materiales y simbólicos en los que encontró sustento. La producción organizada en torno a los grupos de trabajadores de oficio, la particular cultura organizacional y el fuerte sentido de identidad asociado a la empresa nos permiten comprender la lógica de la acción desarrollada por los trabajadores.

La complejidad de la construcción naval hace que los trabajadores de oficio $^{16}$ ocupen un lugar central en el proceso productivo, en tanto encargados de organizar y mantener la cohesión del grupo y controlar de modo informal la producción. En el marco de una paralización casi total de la producción y sin una estrategia empresarial de reestructuración modernizante, el trabajo grupal y la organización por oficios en el ARS permitió reactivar la producción utilizando las reglas informales del trabajo y las rutinas y capacidades productivas acumuladas en la empresa. ${ }^{17}$

Por otro lado, el origen y dependencia de la Marina impregnó a la empresa de rasgos culturales peculiares. Dado que el ARS se concebía como una empresa al servicio del Estado nacional, la dirección del astillero promovió entre sus trabajadores un sentimiento fuertemente nacionalista sustentado en el carácter público de la empresa y en su función de afianzar el desarrollo industrial del país. El impulso de este discurso a través de los ańos, sumado a los beneficios materiales y la estabilidad laboral que proveyó tradicionalmente el astillero, forjaron en los trabajadores una fuerte identidad sociolaboral relacionada íntimamente a la empresa.

Esta identidad, asociada al trabajo desempeńado y a la comunidad fabril, cobró visibilidad en la experiencia de la resistencia. El colectivo de trabajadores hizo explícita su identidad en el mismo enfrentamiento con el poder oficial, defendiendo no sólo la fuente de trabajo sino también los valores y premisas (de soberanía y desarrollo industrial nacional, especialmente) que la empresa representaba.

\subsection{YPF: privatización, adaptación y modernización empresarial}

La visión estatista, que concebía la producción petrolera como un recurso estratégico de la nación, fue abandonada en la década de los noventa, cuando el gobierno nacional impulsó la privatización de YPF al considerarla como un mero recurso económico que, entre otras cuestiones, podía aportar divisas para equilibrar el presupuesto nacional y afrontar los pagos de la deuda externa. Cabe señalar que antes de poner en práctica este

\footnotetext{
${ }^{16}$ Citando a Vatin podemos definir el sistema de oficios como "una forma de organización del trabajo caracterizada por un recorte flexible de las tareas entre individuos dotados de una gran autonomía en la preparación y ejecución de su trabajo" (2004: 179).

${ }^{17}$ Nos referimos específicamente al mantenimiento de las máquinas herramientas en momentos de paralización de la producción, las adaptaciones de dispositivos para llevar adelante nuevas obras en un contexto de escasez de recursos y el desempeńo polivalente de los trabajadores.
} 
proceso privatizador, se había impulsado una importante desregulación del sector petrolero que abría la posibilidad de que algunas empresas privadas participaran de la producción petrolera, ya sea en las fases de exploración y extracción o en la de refinación.

En lo que respecta a la empresa propiamente dicha, el 31 de diciembre de 1990 el Poder Ejecutivo nacional firmó el decreto 2,778, ${ }^{18}$ que transformaba a YPF Sociedad del Estado en YPF, S.A., permitiendo de esta forma que la empresa fuera cotizada en acciones y vendida en el mercado de capitales.

La privatización de YPF significaba el desprendimiento de muchos de sus activos históricos: cierre, venta o asociación en refinerías, venta de la flota petrolera y los camiones tanques, asociación con capitales privados en áreas centrales y puertos y boyas, cierre o venta de plantas de despacho, cierre de proveedurías, venta del taller naval, asociación o venta de oleoductos y poliductos, etcétera.

El proceso de venta siguió en octubre de 1992 cuando, por la ley 24,145, se decidió privatizar el resto del capital social disponible de YPF, s.A. Pero fue en el año 1994, luego de la reforma constitucional, que se transfirió en forma integral a las provincias el dominio público de los yacimientos de hidrocarburos.

Si bien en estos primeros años de la privatización de YPF la venta de acciones se realizó de manera atomizada, para impedir que éstas fueran controladas por un solo operador nacional o internacional, en 1999 esta situación cambió abruptamente.

En marzo de 1995 se aprobó la ley 24,474 que daba vía libre a la venta del capital accionario restante que aún estaba en manos del Estado. Esto permitió que se hiciera efectiva la venta de 14\% de las acciones que éste tenía todavía en su poder. Así, luego de varias idas y venidas, de debates en las cámaras legislativas, de disputas entre varios grupos económicos locales y extranjeros, de la venta del porcentaje accionario de la empresa que le quedaba al Estado y del cambio del estatuto de la firma petrolera que impedía la compra de la mayoría accionaria a un solo inversor, el grupo español Repso ${ }^{19}{ }^{19}$ logró comprar casi $99 \%$ de la acciones de la empresa petrolera después de hacer una oferta hostil que fue bien vista por los antiguos accionistas.

\footnotetext{
${ }^{18}$ Reglamentario de la ley 26,696 de Reforma del Estado.

${ }^{19}$ Tradicionalmente Repsol había sido una empresa de tamaño pequeño y de baja integración vertical, concentrada en la refinación y comercialización de crudo para el mercado espańol. Sus actividades de exploración se concentraban en el norte de África, donde extraía $60 \%$ de su petróleo. A principios de la década de los noventa adoptó la estrategia de crecer considerablemente en ese segmento de mercado. Se escogió Argentina como el punto central de expansión en América Latina (García, 2002).
} 
En síntesis, la desestatización de YPF se organizó en tres etapas diferentes. La primera consistió en dejar la empresa en un tamaño óptimo, luego de la desregulación del sector petrolero. La segunda fue la reestructuración productiva que significó la puesta en práctica de una nueva estrategia empresarial y la reducción de la plantilla de trabajadores petroleros. Una vez completadas estas dos etapas se procedió a la última fase de privatización, que fue realizada sobre todo en dos momentos diferentes: entre 1993 y 1995 y en 1999 .

Una de las consecuencias más importantes que trajo aparejada la privatización de YPF fue la drástica disminución en el número de empleados. Este proceso se debió no sólo a la fragmentación de los activos de YPF antes de su privatización, que derivó en una transferencia de puestos de trabajos a otras empresas, sino también a una estrategia de racionalización de personal viabilizada a partir de una política de retiros voluntarios ${ }^{20} \mathrm{y}$ otras formas de desvinculación, como los despidos y las cesantías. ${ }^{21}$

La nueva política empresarial traía consigo una reformulación en la gestión de la fuerza laboral, en la que se daba mayor importancia a los saberes profesionales y técnicos, se mantenía en el mismo nivel a los administrativos y se declaraba prescindible a una gran cantidad de operarios, que eran en su mayor parte trabajadores idóneos, dueños de un saber hacer específico construido con base en la experiencia de trabajo.

El proceso de racionalización de personal fue la medida inicial de la reestructuración productiva que se implementó en la empresa, pues con la reducción de la plantilla de trabajadores se puso en práctica una reorganización en la gestión de mano de obra. Desde entonces la estrategia de la empresa es contratar personas jóvenes, con títulos técnicos, terciarios o universitarios, que posean conocimientos de idiomas.

La productividad de la empresa aumentó entonces considerablemente, ya que si, como afirma Vatin (2004), tenemos en cuenta que ésta se mide como el cociente entre la producción de metros cúbicos de petróleo y la cantidad de trabajadores, resulta claro que con los años se pudo alcanzar un importante incremento de la productividad mediante la racionalización en cuanto al número de personal y la incorporación de nuevas tecnologías ahorradoras de mano de obra.

La política de reestructuración también significó la implementación de un proceso de modernización empresarial, que incluyó la puesta en

\footnotetext{
${ }^{20} \mathrm{El}$ retiro voluntario consistía en el acuerdo de que el trabajador abandonara su puesto a cambio de un pago indemnizatorio que contemplaba los ańos de servicio y la categoría laboral.

${ }^{21}$ Si comparamos la cantidad de trabajadores que YPF tenía en 1989, año en que la empresa tenía el mayor número de agentes, con los 5,690 que, según el Boletín de Informaciones Petroleras (1995), la empresa tenía en 1995, podemos señalar que se produjo la desvinculación de 31,356 trabajadores, es decir, $84.6 \%$ de su dotación de personal.
} 
práctica de un importante proceso de externalización y la incorporación de innovaciones tecnológicas.

El proceso de externalización se plasmó en la terciarización de una serie de actividades de mantenimiento y logística que antes realizaba la empresa. Así, luego de la privatización se puso en práctica la externalización de estas actividades, para lo cual se subcontrató una serie de proyectos conformados por ex agentes petroleros que tenían el conocimiento específico, gracias a sus años de trabajo en la empresa petrolera estatal. De esta forma la empresa comenzó a transformar en variables costos que hasta ese entonces eran fijos, y a aumentar considerablemente sus ganancias.

En cuanto a las innovaciones tecnológicas se produjo la incorporación de nueva tecnología en las fases de exploración, producción, refinación y marketing. Con esto se pretendía introducir cambios en las rutinas organizacionales y productivas, y diversificar la cantidad de productos finales obtenidos.

Sin embargo, la incorporación de esta tecnología no significó desembolsar inversiones importantes, pues en los años ochenta el Estado había realizado cuantiosas inversiones en la industria petrolera con el objetivo de modernizar la empresa, lo cual aprovecharon los directivos una vez que ésta fue privatizada.

Así, luego de la privatización, reestructuración productiva y modernización empresarial implementada, esta empresa, a cargo del grupo económico Repsol YPF, se transformó en una de las 10 mayores petroleras privadas del mundo y en la mayor compañía privada energética en Latinoamérica en términos de activos.

\subsubsection{Las estrategias de los actores frente al cambio}

El proceso de privatización, reestructuración y modernización empresarial en cierta forma fue posible gracias a las estrategias adoptadas por los principales actores participantes: el gobierno nacional, en tanto dueño de la compañía petrolera, y los representantes de los trabajadores.

Con respecto al primero, es importante señalar que fue el Poder Ejecutivo quién propició la desestatización de YPF. Los argumentos que se esgrimieron para justificar esta decisión fueron el crónico desequilibrio presupuestario que absorbían todos los argentinos, la ineficiencia empresarial con que se manejaba y la necesidad de obtener fondos para afrontar los pagos de la deuda externa. De esta forma se sostenía que con la privatización se lograría una mayor eficiencia en la producción o explotación de la actividad, que traería en consecuencia mayor calidad y cantidad del producto a menor precio, mejorando además la situación social, ya que 
al producir más disminuiría el desempleo (Cervo, 2003). El objetivo que guiaba la desestatización era transformar YPF en una empresa rentable, productiva y competitiva internacionalmente.

Ahora bien, en relación con este argumento resulta interesante señalar que si bien la situación de la empresa era delicada, ello no significaba que no fuera rentable, pues la decadencia de la empresa era en realidad consecuencia de que los distintos gobiernos en el poder no la habían conducido de manera eficiente. Como señalan numerosos estudios, de tiempo atrás el Estado no obtenía rentabilidad de sus numerosas actividades, la burocracia reinaba en todos sus sistemas administrativos y comerciales, se utilizaban sus recursos para financiar déficits de otros sectores, algunas agencias estatales mantenían importantes deudas con la compañía petrolera, etcétera (Kosulj y Bravo, 1993; Olivieri, 1991).

Por otro lado se encuentra el Sindicato Unido Petroleros del Estado (SUPE), organización que surgió y creció al amparo de los diferentes gobiernos con orientación política peronista. De esta forma, a lo largo de su historia el SUPE estableció una estrecha relación con los gobiernos peronistas en el poder, que propició la disminución de la lucha sindical como estrategia de presión para alcanzar la satisfacción de las necesidades de los trabajadores de YPF. La fuerte relación entre ellos posibilitó el desarrollo de una estrategia articulada de la que ambos se favorecían: el gobierno amparaba sus reivindicaciones concediendo al sindicato los beneficios laborales que éste reclamaba y, en contrapartida, la organización sindical daba su apoyo a las políticas peronistas transformándose en un transmisor oficial de la política gubernamental.

En los años noventa esta situación cambió rotundamente, pues el gobierno peronista de Menem impulsó el desmantelamiento de la empresa petrolera estatal. Esta política fue un golpe directo al corazón del poder sindical, pues, por una lado, el supe perdió el importante rol que tenía en el mercado interno de trabajo de la empresa y, por otro, al reducirse la cantidad de trabajadores de YPF, sufrió una importante disminución en su número de afiliados y vio ampliamente recortados sus recursos económicos.

De manera paradójica, el gobierno peronista al que había brindado todo su apoyo en la elecciones presidenciales de 1989, una vez en el poder impulsó una serie de medidas neoliberales que propiciaron la desarticulación del poder político y económico del sindicato.

Ante esta situación el supe, junto con otros sindicatos peronistas afiliados a la Confederación General del Trabajo (CGT), inició medidas de fuerza. A pesar de ello, el tono de sus acciones fue más el de queja que el de confrontación y su reclamo principal se centró en pedir mayor participación en el proceso de toma de decisiones (Margheritis, 2003: 209). 
Esta estrategia la sostuvo el sindicato con el argumento de la supuesta inevitabilidad de los cambios ante las reformas estructurales que se estaban sucediendo.

Así, el supe decidió aceptar el proceso en general pero negociando con el gobierno ciertos condicionamientos a las reformas institucionales. El objetivo que perseguía era aumentar sus recursos organizativos para compensar la decadencia de los recursos políticos e industriales y ganar una mayor autonomía, tanto con respecto al Estado como a la capacidad movilizadora de las bases, influida por las condiciones del mercado laboral (Murillo, 1997).

En un cambio de estrategia, el supe desarrolló una forma de supervivencia organizativa al convertirse en un sindicato de negocios (Orlansky, 1997). Ante estas transformaciones y la pérdida importante de poder, decidió aceptar la privatización y negociar una serie de concesiones, entre las que destacan: la participación accionaria en la empresa privada a partir del Programa de Propiedad Participada, ${ }^{22}$ subsidios para crear obra social (OSPE), el reconocimiento del monopolio de la representación sindical a pesar de la existencia de otro sindicato de trabajadores en el sector (la Federación Argentina Sindical del Petróleo y el Gas Privados, FASPYGP) y la conformación de proyectos para prestar servicios a la empresa (Orlansky y Makon, 2002: 5).

Ahora bien, ¿por qué razón los dirigentes nacionales petroleros decidieron adoptar este tipo de estrategia, en lugar de subordinarse totalmente o resistir en forma activa? Si se tiene en cuenta la deslealtad del gobierno en el poder, podría esperarse que el SUPE ofreciera resistencia, oponiéndose activamente a la privatización de YPF, mediante un paro de la producción, la movilización masiva de los trabajadores y la defensa hasta las últimas consecuencias de los valores ideológicos que habían dado origen a la empresa petrolera estatal y la organización sindical.

Por otro lado, también se puede señalar que, dada la íntima relación que la cúpula petrolera sindical tenía con el presidente, ${ }^{23}$ el supe pudo haber apoyado abiertamente las iniciativas políticas nacionales subordinándose al gobierno sin negociar nada a cambio.

Con esto queremos decir que si bien el sindicato petrolero tomó un papel colaboracionista al optar por una estrategia sindical de supervivencia organizativa, tuvo en sus manos la posibilidad de ensayar otro tipo de estrategias, pero prefirió adaptarse a las nuevas reglas del juego y transformarse en un sindicato de negocios. Sobrevivir en el nuevo contexto,

\footnotetext{
${ }^{22}$ Este programa establecía que $10 \%$ de las acciones de la empresa petrolera estatal pertenecían a sus trabajadores.

${ }^{23}$ Diego Ibañes, secretario general de la Federación supe en ese momento, era amigo personal del presidente de la nación.
} 
mantener cierta cuota de poder, ese fue el objetivo que decidió privilegiar (Muñiz, 2006)

Una de las principales razones que influyeron en la decisión de llevar a cabo esta estrategia tiene que ver con la organización política interna del gremio, pues el SUPE era un sindicato verticalista, en el que la cúpula se había distanciado de las bases obreras que decía representar. Este alejamiento le permitió entonces tomar decisiones a solas sin demasiada presión de sus afiliados, que se encontraban diseminados a lo largo del territorio nacional.

Mediante una política colaboracionista la Federación supe se negó a resistir, desmovilizando a los trabajadores al argumentar que ante semejantes reformas estructurales el sindicato nada podía hacer. Dado que su poder estaba totalmente erosionado debía adaptarse a los nuevos tiempos para no desaparecer.

Así, en el caso de YPF, consideramos que el éxito de la privatización, reestructuración y modernización empresarial en parte estuvo garantizado por las estrategias de los trabajadores para adaptarse a una entorno económico cambiante: tanto el gobierno nacional como los representantes de los trabajadores propiciaron en definitiva la transformación de la empresa petrolera.

\section{Conclusiones}

Como hemos observado a lo largo de este trabajo, la trayectoria seguida por las empresas no se explica única y acabadamente por lógicas externas, como podrían ser las condiciones cambiantes de los mercados o las políticas macroeconómicas implementadas, que habrían impuesto cambios universales y homogéneos. Al contrario, identificar las diferencias en las trayectorias empresariales nos lleva a concluir que las acciones de los actores al interior de cada organización productiva frente a las restricciones u oportunidades que presenta el entorno, son un elemento ineludible del análisis.

En este sentido, planteamos que las variables que explican las diferentes trayectorias de las firmas aquí estudiadas son las características propias de cada empresa, la coyuntura internacional del sector de actividad y las estrategias desarrolladas por los actores frente a la política de privatización.

En relación con las características de las empresas, YPF era una compañía nacional de relevancia económica fundamental, que producía para los mercados interno y externo, propiciaba el desarrollo socioeconómico de las regiones del país en donde se emplazaba y ocupaba la mayor cantidad de trabajadores de las empresas públicas. Por su parte, el ARs era una empresa mediana, localizada en una única unidad fabril y con un claro 
perfil para el mercado interno. Estas características explican el diferente interés que pusieron el gobierno nacional y los grupos privados en el proyecto privatizador de cada una de estas empresas, así como la distinta disponibilidad de recursos con los que contaba cada uno de los sindicatos a la hora de negociar frente al Estado.

Cabe recordar que en ninguno de los casos analizados la opción de la privatización implicaba un mejoramiento en términos de desarrollo económico regional. La implementación de políticas de ajuste y racionalización a la producción y el empleo en estas empresas tuvo en el entramado productivo regional un alto costo en términos sociales, laborales y de creación de valor local. El aumento relativo de la rentabilidad y productividad en las empresas privatizadas no logró equilibrar, en términos de resultados globales, los puestos de trabajo, las capacidades tecnológicas, los conocimientos específicos y los eslabonamientos productivos locales que se perdieron a raíz de las políticas de reestructuración implementadas.

La coyuntura de cada sector de actividad fue otro factor que influyó en el devenir de las empresas ya que, mientras que el sector petrolero internacional presentaba una expansión continua dado el sostenido aumento de la demanda de sus productos derivados, la construcción naval sufría una fuerte recesión mundial desde una década atrás y era objeto de un profundo proceso de racionalización y reestructuración. El interés privado, por consiguiente, planteaba presiones y condiciones diferentes en cada caso.

Respecto a las estrategias de los actores, en primer lugar, la lógica hegemónica de privatización y ajuste encarada por el gobierno en los años noventa la enfrentaron de manera diversa los trabajadores de cada empresa. ${ }^{24}$ Los trabajadores petroleros llevaron a cabo una estrategia de aceptación negociadora de la privatización, a cambio de obtener beneficios específicos; mientras que los del ARs tuvieron una actitud de oposición y resistencia a la privatización y al nuevo modelo macroeconómico.

El sindicato de YPF llevó adelante una estrategia acorde con su modelo histórico de actuación: negociación directa con el gobierno peronista en el poder en busca de beneficios laborales y/o recursos organizativos para el gremio. Sumado a esto, la separación de las bases de la cúpula sindical y la falta de tradición de lucha promovieron una estrategia basada en una lógica principalmente adaptativa.

El sindicato del ARS, por el contrario, opuso una resistencia sustentada en su tradición de lucha y movilización laboral, una estructura demo-

\footnotetext{
${ }^{24}$ Es necesario resaltar que a pesar de que no se evidencia homogeneidad en las trayectorias empresariales, la estrategia de adaptación (y no de resistencia) de los sindicatos frente a la política de privatización en la Argentina de los años noventa fue claramente hegemónica.
} 
crática gremial y una cultura organizacional fuerte que promovía la identificación con la empresa.

Los actores estatales, por su parte, también tuvieron posicionamientos diferentes en cada una de las empresas. En el caso de YPF el gobierno nacional llevó adelante la privatización y reestructuración de la empresa sin importar los costos que debía asumir por ello; mientras que en ARs, los gobiernos nacional y provincial, así como la Marina, buscando satisfacer su propio interés, tuvieron estrategias contradictorias que no lograron alcanzar sus máximos objetivos y terminaron favoreciendo la permanencia del astillero en la órbita estatal.

En síntesis, los actores participantes en cada una de las organizaciones, persiguiendo objetivos diferentes y dentro de ciertos límites, llevaron a cabo estrategias que consideraron racionales en el marco de la situación planteada por la transformación del contexto, haciendo uso de los diversos recursos disponibles.

En este análisis enfatizamos que los resultados de la política pública no se pueden predecir por completo ya que la articulación entre las presiones del entorno y el comportamiento de los actores siempre es distinta. La diversidad de las trayectorias aquí analizadas se explica tanto por condiciones estructurales como por los hechos de los actores participantes, lo cual sugiere que los constreñimientos del contexto macroeconómico se deben relativizar si se quiere explorar en profundidad la transformación de las empresas en el tiempo.

En conclusión, los estudios de caso aquí presentados ilustran la relevancia que tienen las estrategias de los actores en las trayectorias de las firmas. Aceptar que ninguna lógica de acción se impone plenamente sobre la organización es el primer paso para dar cuenta de la real complejidad que tienen las relaciones sociales desarrolladas en su interior. Revalorar el lugar de la acción de los sujetos en la organización, creemos, constituye el acercamiento más adecuado para dar cuenta del modo en que los cambios globales recientes afectan al mundo del trabajo. Se trata, en última instancia, de dar cuenta de los condicionantes del contexto y los márgenes de libertad que surgen en el mismo y por los cuales se filtran las acciones de los sujetos.

\section{Bibliografía}

Aoki, Masahiko (1988), La estructura de la empresa japonesa, Fondo de Cultura Económica, México.

Aoki, Masahiko (2001), Toward a Comparative Institutional Analysis, MIT Press, Cambridge, Mass. 
Astillero Río, Santiago (2004), Presentación oficial de la empresa, Astillero Río Santiago, Ensenada.

Azpiazu, Daniel (1995), "La industria argentina ante la privatización, la desregulación y la apertura asimétrica de la economía”, en D. Aspiazu y H. Nochteff (1995), El desarrollo ausente, FLACsoNorma, Buenos Aires.

Basualdo, Eduardo (2000), Concentración y centralización del capital en la Argentina durante la década del noventa, Universidad Nacional de Quilmes-Flacso, Buenos Aires.

Bernoux, Philippe (1985), La sociologie des organizations, Seuil, París.

Bernoux, Philippe (2002), "Le changement dans les organisations. Entre structures et interactions", Relations Industrielles/Industrial Relations, 57 (1), Université Laval, Quebec, pp. 77-99.

Boletin de Informaciones Petroleras (1989), 17, Buenos Aires.

Boletin de Informaciones Petroleras (1995), 42, Buenos Aires.

Boyer, Robert (1987), La flexibilidad del trabajo en Europa, Ministerio de Trabajo y Seguridad Social, Madrid.

Burns, Toms y George M. Stalker (1966), The Management of Innovation, Tavistock, Londres.

Bustelo, Pablo (2003), "Enfoque de la regulación y economía política internacional, ¿paradigmas convergentes?”, Revista de Economía Mundial, 8, Buenos Aires, pp. 123-145.

CEP (Centro de Estudios para la Producción) (2005), La industria naval en la Argentina, Secretaría de Industria, Buenos Aires.

Cervo, Augusto (2003), "La privatización de YPF y sus consecuencias", mimeo, Buenos Aires.

Coase, Ronald (1937), "The nature of the firm”, Economica, 4, Londres, pp. 386-405. 
Coller, Xavier y Roberto Garvía (2004), Análisis de organizaciones, Centro de Investigaciones Sociológicas-Siglo XXI, Madrid.

Crozier, Michel y Erhard Friedberg (1990), El actor y el sistema. Las restricciones de la acción colectiva, Alianza, México.

Dombois, Rainer y Ludger Pries (1993), “Modernización empresarial y cambios en las relaciones industriales en América Latina y Europa”, en Raimer Dombois y Ludger Pries (eds.), Modernización empresarial: tendencias en América Latina y Europa, Fundación Friedrich Ebert, Caracas.

FINA (Federación de la Industria Naval Argentina) (2001), "Evolución reciente de la industria naval argentina", documento de trabajo, FINA, Buenos Aires.

Fishlow, Albert (1990), "The Latin American State", The Journal of Economic Perspectives, 4 (3), Pittsburgh, American Economic Association Publications, Nueva York, pp. 61-74.

Frassa, Juliana (2006), "Políticas públicas de desregulación y sus consecuencias sobre la producción y el empleo. El caso de la política naviera y la industria naval argentina", Revista Informe IEFE, 139, La Plata, pp. 39-52.

García, Marcelo (2002), "Las operadoras petroleras: Repsol-ypF”, Centro Regional de Estudios Económicos de la Patagonia Central, www.creepace.com.ar.

Kosacoff, Bernardo (2000), El desempeño industrial argentino más allá de la sustitución de importaciones, CEPAL, Buenos Aires.

Kozulj, Roberto y Víctor Bravo (1993), La política de desregulación petrolera argentina. Antecedentes e impactos, Centro Editor de América Latina-IDEE, Buenos Aires.

Lawrence, Paul R. y Jay W. Lorsch (1967), Organization and Environment. Managing differentiation and integration, Harvard University Press, Cambridge.

Linhart, Danièle (1997), La modernización de las empresas, Asociación Trabajo y Sociedad-Conicet, Buenos Aires. 
Margueritis, Ana (2003), "La privatización de Yacimientos Petrolíferos Fiscales y actividades afines", en Ana Margueritis (ed.), Ajuste y reforma en Argentina (1989-1995). La economía politica de las privatizaciones, Nuevo Hacer, Buenos Aires, pp. 195-234.

Montes, José (1999), Astillero Río Santiago, su historia y su lucha relatada por sus trabajadores, La Verdad Obrera, Buenos Aires.

Muñiz Terra, Leticia (2006), "La erosión del poder sindical en un escenario de privatización: el caso del Sindicato Unido Petrolero del Estado", Revista Question, 12, Universidad Nacional de La Plata, La Plata, pp. 1-21.

Murillo, Victoria (1997), "La adaptación del sindicalismo argentino a las reformas de mercado en la primera presidencia de Menem", Desarrollo Económico, 37 (147), Buenos Aires, pp. 22-41.

Nelson, Richard y Sidney Winter (1982), An Evolutionary Theory of Economic Change, Harvard University Press, Cambridge.

OIT (Organización Internacional del Trabajo) (1998), "El empleo y las relaciones de trabajo en las refinerías de petróleo", Informe para el debate, Programa de actividades sectoriales, Ginebra.

Olivieri, Carlos (1991), "YPF, un modelo de privatización para el mundo", Boletín de Información Petrolera, 25, año viII, Buenos Aires.

Orlansky, Dora (1997), "Reforma del Estado, reestructuración laboral y reconversión sindical. Argentina 1989-1995", Revista Estudios Sociológicos, xv (45), El Colegio de México, México, pp. 46-68.

Orlansky, Dora y Andrea Makón (2002), "De la sindicalización a la informalidad. El caso de Repsol-ypF", ponencia presentada en el seminario Programa de Estudios Internacionales, Buenos Aires.

Pérez Pradal, Cecilia (2003), "Contra el naufragio. Un estudio sobre los conflictos laborales en el caso de Astilleros Río Santiago: 19891999”, tesinas finales de sociología, Universidad Nacional de La Plata, La Plata.

Revista Repsol YPF (2004), 1, Buenos Aires. 
Reynaud, Jean Daniel (1989), Les régles de jeu. L'action collective et la regulation sociale, Armand Colin, París.

Simon, Herbert (1969), Sciences des Systèmes. Sciences de l'Artificiel, Dunod, París.

Svampa, Maristella y Sebastián Pereyra (2003), Entre la ruta y el barrio. La experiencia de las organizaciones piqueteras, Biblos, Buenos Aires.

Vatin, François (2004), Trabajo, ciencia y sociedad, Asociación Trabajo y Sociedad-CEIL-Conicet, Buenos Aires.

Williamson, Oliver (1985), The Economic Institutions of Capitalism, The Free Press, Nueva York.

Recibido: 26 de diciembre de 2007. Aceptado: 3 de agosto de 2009.

Juliana Frassa. Es licenciada en sociología por la Universidad Nacional de La Plata (UNLP) y magíster en ciencias sociales del trabajo por la Universidad de Buenos Aires (UBA). Actualmente cursa el doctorado en ciencias sociales en la uba. Es docente de la UNLP y becaria del Conicet con sede de trabajo en el CEIL-PIETTE, donde desarrolla su tesis doctoral sobre estrategias laborales y empresariales en una empresa pública en contextos de privatización. Sus líneas de investigación son: trayectorias empresariales de empresas estatales, el papel de la cultura organizacional y los saberes productivos en la supervivencia de dichas empresas. Ha publicado varios artículos en revistas nacionales e internacionales y ha participado en proyectos de investigación en las áreas de sociología y economía del trabajo.

Leticia Muñiz-Terra. Es doctora en ciencias sociales por la Universidad de Buenos Aires (UBA), magíster en ciencias sociales del trabajo por la misma universidad; realizó estudios de profesorado y licenciatura en sociología en la Universidad Nacional de La Plata (UNLP). Actualmente es docente en la UNLP e investigadora del Consejo Nacional de Investigaciones Científicas y Técnicas (CONICET) con lugar de trabajo en el Centro Interdisciplinario de Metodología de las Ciencias Sociales (Cimecs-IdICS, UNLP-CONICET). Sus líneas de investigación son: trayectorias laborales como concepto teórico-metodológico, reestructuraciones empresariales. 
Ha publicado varios artículos en revistas nacionales e internacionales y ha participado en proyectos de investigación en las áreas de sociología del trabajo y de la pobreza.

Alejandro Naclerio. Es doctor en ciencias económicas por la Universidad París 13. Es magíster (o Diplôme d'études approfondies) en organización industrial, innovaciones y estrategias internacionales por la Universidad de París 13. Es magíster en ciencias sociales del trabajo por el Centro de Estudios Avanzados de la Universidad de Buenos Aires. Es licenciado en economía por la Universidad Nacional de La Plata. Es profesor en la UNLP y la UNQUi. Es coordinador del área Ciencia y Tecnología del CEIL-PIETTE del Conicet. Ha participado y coordinado varios proyectos de investigación. Sus líneas de investigación son: economía de las innovaciones y/o del conocimiento y estrategias de los actores en los sistemas económicos. 